\title{
Knowledge, Attitude and Practice of Cervical Carcinoma Screening among Bangladeshi Women
}

\author{
Ayesha Najma Nur ${ }^{{ }^{*}}$ \\ Juthi Bhowmik ${ }^{2}$ \\ Shiuly Chowdhury ${ }^{3}$ \\ Shirin Akter Begum ${ }^{4}$
}

'Department of Obstetrics \& Gynaecology Center for Women and Child Health Ashulia, Dhaka, Bangladesh.

${ }^{2}$ Department of Obstetrics \& Gynaecology Bangladesh Institute of Health \& Science Dhaka, Bangladesh.

${ }^{3}$ Department of Obstetrics \& Gynaecology Bangabandhu Sheikh Mujib Medical University Dhaka, Bangladesh.

${ }^{4}$ Department of Gynaecological Oncology Bangabandhu Sheikh Mujib Medical University Dhaka, Bangladesh.

\author{
*Correspondence to: \\ Dr. Ayesha Naima Nur \\ Consultant \\ Department of Obstetrics \& Gynaecology \\ Center for Women and Child Health \\ Ashulia, Dhaka, Bangladesh \\ Mobile : +8801711902285 \\ Email : ayeshanajmanur@gmail.com
}

Date of Submission : 21.09 .2020

Date of Acceptance ： 06.01 .2021

www.banglajol.info/index.php/CMOSHMCJ

\begin{abstract}
Background: The uterine cervix is the commonest site for female genital cancer. In developing countries, carcinoma cervix is the most common malignancy in females and a major public health problem. It is reported In Bangladesh that the prevalence of carcinoma cervix is $20 \%$ among all types of cancer affecting females. To determine the level of knowledge, attitude and practice among Bangladeshi women about screening of cervical carcinoma

Materials and methods: A cross-sectional study was conducted on married women above the age of 20 years, attending OPD of Obstetrics \& Gynecology, Medicine and Surgery of BSMMU from January 2013 to June 2013. By using purposive sampling technique 225 respondents were enrolled in the study.

Results: Mean age of the respondents was 43.34 years with a standard deviation of \pm 12.49 years. Most of the respondents (96\%) were Muslim and from urban areas. More than two-thirds of the respondents (71.1\%) were educated up to secondary level. More than $80 \%$ respondents were housewives. About three-fourth of the respondents were form middle class families. Only $20 \%$ could mention cervical cancer as the leading cancer among women. About 20\% respondents knew that early and multiple marriages were the two risk factors for cervical cancer. Most of the respondents (93.3\%) believed that cervical cancer is dangerous disease and was able to mention smoking as one of the important risk factors. About one-third respondents knew that terms Pap's smear and VIA. But most of the respondents did not undergo any screening procedure under the assumption that the screening was not necessary. It was found that respondents with higher education level possessed good knowledge regarding cervical cancer. It was also true for respondents whose husbands were more educated. Higher education level was positively correlated with good attitude/practices. The respondents who had good knowledge about cervical cancer showed good attitude/practice regarding the same.
\end{abstract}

Conclusion: The knowledge regarding cervical cancer among the participants was not satisfactory. Although most of the participants believed that cervical cancer is dangerous disease few really knew that it is preventable. Higher education level was positively correlated with good knowledge and good attitude/practices regarding cervical cancer. Long term education for women should be started to provide the needed information regarding cervical cancer screening.

Key words : Cervical carcinoma; Uterine cervix; Female genital cancer; Multiple marriages.

\section{INTRODUCTION}

The uterine cervix is the commonest site for female genital cancer ${ }^{1}$. About $5 \%$ of all women dying of malignant diseases is due to cervical cancer ${ }^{1}$. In developing countries, carcinoma cervix is the most common malignancy in females and a major public health problem. The second most common is breast cancer, the ratio is 3:1 but in developed countries the ratio of cervical cancer and breast cancer is $1: 3^{2}$. The rate of 
cervical cancer is decreasing gradually in developed countries due to awareness about cervical cancer and routine screening test $^{3}$. In Bangladesh a study has shown that the prevalence of carcinoma cervix is $20 \%$ among all types of cancer affecting females ${ }^{4}$.

In Bangladesh there is no population -based cancer registration but according to the annual report of hospital-based cancer registry of NICRH in 2005, carcinoma cervix tops the list of common cancer among the females. Carcinoma cervix accounts for $7.8 \%$ of all gynaecological patients and $70 \%$ of all gynaecological malignancies admitted in BSMMU in the year $2007^{5}$.

Cervical cancer is a preventable condition and over $95 \%$ of patients with carcinoma cervix can be cured by early detection ${ }^{6,7}$. Most cervical lesions do not progress to carcinoma and those that do, progress slowly, making carcinoma cervix largely preventable through effective screening ${ }^{8}$. Marked decrease in cervical carcinoma incidence and mortality have been achieved by systemic population-based cytology screening programmes in developed nations from as early as the 1960 's ${ }^{9}$. Therefore, the awareness, knowledge and practice of carcinoma screening among the target-group is of utmost importance in the prevention of the disease.

Screening tests for cervical cancer includes Pap's smear test, VIA \& HPV DNA test. PAP smear screening has a specificity of approximately $99 \%$ and is better for high grade and invasive lesions ${ }^{9}$. The test is less specific for low grade CIN. Over diagnosis of these lesions is common and is in part due to the test's inability to distinguish low-grade CIN from HIV infection. The sensitivity of pap smear screening has been reported to range from 40 to 70 percent. The generally accepted false negative rate is $15-25$ percent $^{9}$. Due to the long period associated with the precursor lesion (CIN) this false negative rate does not compromise screening strategies as long as smears are performed frequently enough ${ }^{9}$.

The frequency of screening is also influenced by the sensitivity of the test, making certain assumptions about the underlying incidence of cancer. It has been estimated that in Western countries screening a woman every 5 years between the ages 20 and 64 confers $84 \%$ protection against invasive cancer. Increasing the frequency of screening to 3 yearly enhances protection to 91 percent and annual screening brings it up to 93 percent. The remaining 7 percent represents either missed cases due to a lack of sensitivity of the test or rapidly growing cancers, which will pass through pre-invasive stage within 1 year'.

The US preventive services task-force recommended Pap's smear at least every 3 years for women who have been sexually active. After 3 or more consecutive negative results the test can be done less frequently at the diecretion of the physician ${ }^{10}$.

In our country VIA (Visual inspection) is the method of choice for screening due to easy affordibility and feasibility. Cases that seem suspicious are recommended for colposcopy, which is direct visualization of the cervix. HPV vaccine is a primary prevention of cervical carcinoma.

\section{MATERIALS AND METHODS}

A cross-sectional study was conducted on married women above the age of 20 years, attending OPD of Obstetrics \& Gynecology, Medicine and Surgery of BSMMU from January 2013 to June 2013. By using purposive sampling technique 225 respondents were enrolled in the study. All the data were checked and edited after collection. Then data entered into computer, with the help of SPSS for Windows version 17 software. An analysis plan was developed keeping in view with the objectives of the study. p-value of 0.05 or less was considered as significant.

\section{RESULTS}

Table I : Age group of the respondents $(\mathrm{n}=225)$.

\begin{tabular}{lcc} 
Age group (Yrs) & Frequency & Percent \\
$18-25$ & 10 & 4.4 \\
$26-35$ & 68 & 30.2 \\
$36-45$ & 47 & 20.9 \\
$46-55$ & 45 & 20.0 \\
$56-65$ & 51 & 22.7 \\
66 & 4 & 1.8 \\
Total & 225 & 100.0 \\
\hline
\end{tabular}

Mean \pm SD $($ Range $)=43.34 \pm 12.49$ (18-72)

Table II : Proportions (\%) of the respondents who pointed out early marriage as the cause of cervical cancer.

\begin{tabular}{lcr}
$\begin{array}{l}\text { Early marriage accounts } \\
\text { for cervical cancer }\end{array}$ & Frequency & Percent \\
Yes & 28 & 12.4 \\
No & 10 & 4.4 \\
Do not know & 187 & 83.1 \\
Total & 225 & 100.0 \\
\hline
\end{tabular}

Table III: Proportions (\%) of the respondents who mentioned multiple marriages as the cause of cervical cancer.

\begin{tabular}{lrr}
$\begin{array}{l}\text { Multiple marriage accounts } \\
\text { for cervical cancer }\end{array}$ & Frequency \\
Yes & 17 & 7.6 \\
No & 6 & 2.7 \\
Do not know & 202 & 89.8 \\
Total & 225 & 100.0 \\
\hline
\end{tabular}

Table IV : Proportions (\%) of the respondents who indicated husband's multiple marriages as the cause of cervical cancer.

\begin{tabular}{lrr}
$\begin{array}{l}\text { Husband's multiple marriage } \\
\text { accounts for cervical cancer }\end{array}$ & Frequency & Percent \\
Yes & 16 & 7.1 \\
No & 6 & 2.7 \\
Do not know & 203 & 90.2 \\
Total & 225 & 100.0 \\
\hline
\end{tabular}


Table $\mathbf{V}: \mathrm{P}$ roportions (\%) of the respondents who believed cervical cancer is dangerous.

$\begin{array}{lrr}\text { Cervical cancer is dangerous } & \text { Frequency } & \text { Percent } \\ \text { Yes } & 210 & 93.3 \\ \text { No } & 5 & 2.2 \\ \text { Do not know } & 10 & 4.4 \\ \text { Total } & 225 & 100.0\end{array}$

Table VI : Proportions (\%) of the respondents who thought that cervical cancer is preventable.

$\begin{array}{lrr}\text { Cervical cancer is preventable } & \text { Frequency } & \text { Percent } \\ \text { Yes } & 52 & 23.1 \\ \text { No } & 3 & 1.3 \\ \text { Do not know } & 170 & 75.6 \\ \text { Total } & 225 & 100.0\end{array}$

Table VII : The means of cervical cancer screening according to the respondents.

\begin{tabular}{lcr} 
How cervical cancer & Frequency & Percent \\
Examined & & \\
VIA & 38 & 16.9 \\
Pap's smear & 37 & 16.4 \\
Colposcopy & 3 & 1.3 \\
Others & 22 & 9.8 \\
Do not know & 125 & 44.4 \\
Total & 225 & 100.0 \\
\hline
\end{tabular}

Table VIII : The places where cervical cancer screening can be done according to the respondents.

$\begin{array}{lrrr}\text { Places of examination } & \text { Count } & \begin{array}{r}\% \text { of } \\ \text { responses }\end{array} & \begin{array}{r}\% \text { of } \\ \text { cases }\end{array} \\ \text { Cancer hospitals } & 59 & 24.3 & 26.2 \\ \text { Medical College Hospitals } & 57 & 23.5 & 25.3 \\ \text { Private clinics } & 6 & 2.5 & 2.7 \\ \text { Do not know } & 121 & 49.8 & 53.8 \\ \text { Total responses } & 243 & 100.0 & 108.0\end{array}$

*Multiple responses

Table IX : Distribution of the respondents according to their cervical cancer screening status.

\begin{tabular}{lrr}
$\begin{array}{l}\text { Underwent cervical } \\
\text { cancer screening }\end{array}$ & Frequency & Percent \\
Yes & 39 & 17.3 \\
No & 186 & 82.7 \\
Total & 225 & 100.0 \\
\hline
\end{tabular}

Table X : Cross-tabulation of the respondents by knowledge index and attitude/practice regarding cervical cancer $(n=225)$.

\begin{tabular}{|c|c|c|c|}
\hline \multirow[t]{2}{*}{ Knowledge index } & \multicolumn{2}{|c|}{ Attitude/Practice } & p-value \\
\hline & $\begin{array}{l}\text { Good } \\
\text { n (\%) }\end{array}$ & $\begin{array}{l}\text { Average } \\
\mathrm{n}(\%)\end{array}$ & $\begin{array}{l}\text { Poor } \\
\text { n (\%) }\end{array}$ \\
\hline Good & $13(40.6)$ & $4(11.8)$ & $2(1.3)<.001 * *$ \\
\hline Average & $19(59.4)$ & $12(35.3)$ & $7(4.4)$ \\
\hline Poor & $0(.0)$ & $18(52.9)$ & $150(94.3)$ \\
\hline Total & $32(100.0)$ & $34(100.0)$ & $159(100.0)$ \\
\hline
\end{tabular}

** Highly significant, $\chi^{2}=139.39(\mathrm{df}=4), \mathrm{p}=<.001$.

\section{DISCUSSION}

Bangladesh is in an epidemiological transition phase and cancer is now one of the leading causes of morbidity and mortality. There is high exposure to risk factors in the workplaces. However, primary prevention and early detection have been neglected in favour of treatment-oriented approaches, without much attention to their cost-effectiveness.

According to the World Health Organization, the number of cases of cancer will double in developing countries by the year 2020. A WHO supported hospital-based registry in the National Institute of Cancer Research and Hospital indicates that cervical and breast cancers are the two leading cancers in women in Bangladesh $^{11}$.

The cost of treatment is very high for an individual and this is also a financial burden to the nation (WHO 2002) ${ }^{11}$. Many of these cases are preventable by simple, cost-effective measures focused on primary and secondary levels of prevention. Assessment of peoples' perceptions of cancer, implementation of an effective awareness programme, and early detection and screening are important components of preventive programmes $\left(\right.$ WHO 2002) ${ }^{11}$. Research in developing, as well as, developed countries has shown a strong association between increased knowledge and early reporting for detection and treatment in the community, thus leading to a better prognosis ${ }^{12}$.

An assessment of the present level of knowledge, attitudes and practices is necessary, and an appropriate Information, Education and Communication (IEC) campaign based on these findings needs to be designed. The objective of the present study was to determine the level of knowledge, attitude and practice among Bangladeshi women about screening of cervical carcinoma.

Two hundred and twenty five married women above the age of 20 years, attending OPD of Obstetrics \& Gynecology, Medicine and Surgery of BSMMU took part in this KAP study. The mean age of participant was 43.34 years with a standard deviation of \pm 12.49 years. Eighty four percent respondents were form urban areas and only $16 \%$ were from rural areas. Most of the respondents were Muslims (96\%). More than two-thirds of the respondents $(71.1 \%)$ were educated from primary to secondary level. The percentages of illiterate and more educated than secondary level were comparatively less. While majority of the respondents $(57 \%)$ were married to persons who had higher secondary level education. Most of the respondents, as expected in our country, were housewives. Service was the leading profession among husbands (65\%).

It was noted that only $7 \%$ respondents came from high socioeconomic class. About three-fourth of the respondents $(74.7 \%)$ belong to the middle class while $18.2 \%$ were from low socioeconomic status.

Only $12.4 \%$ respondents said that they considered early marriage as the causing factor of cervical cancer while only $7.6 \%$ respondents said that they considered multiple marriages as the causing factor of cervical cancer. Most of the respondents 
(90.2\%) did not know weather husband's multiple marriages cause cervical cancer on not.

Respondents were asked about causes of cervical cancer according to their opinion. To most of them (70.7\%) smoking was the cause of the disease. Though this is not true, but this observation clears the important fact that the link of smoking to cancer is well known even to general people.

The respondents were questioned about the means of cervical cancer screening according to their opinion. About $17 \%$ of the respondents told VIA while somewhat equal percentage of the respondents (16.4\%) named Pap's smear as the means. Mutyaba $\mathrm{T}$ et al. study in Uganda reported more than $80 \%$ of the respondents knew about Pap's smear ${ }^{13}$. As they all were hospital workers this finding seems normal for them. Regarding timing half of the respondents told that screening should be done once in life time. Only 4 respondents $(1.8 \%)$ pointed out that that test should be done every three yearly and about $50 \%$ respondents named Cancer Hospitals and Medical College Hospitals as the place of examination.

Most of the respondents (82.7\%) did not undergo cervical cancer screening; the reason behind such behavior was that most of them did not think the screening test was necessary at all while Indian study reported lack of symptoms as the leading cause of non-participation in screening.

It is found that respondents with higher education level possessed good knowledge regarding cervical cancer. It was also true for respondents whose husbands were more educated. No significant associations were noted between knowledge indices and residential and socio-economic status.

Regarding attitude/practice it was found that higher education level was positively correlated with good attitude/practices. Husband's educational level positively influenced the attitude/practice regarding cervical cancer as well. Respondents of good socio-economic status showed better attitude/practice than poor status ( $16.3 \%$ vs. $4.9 \%)$.
Finally knowledge index and attitude/practice regarding cervical cancer were tested for association. The respondents who had good knowledge about cervical cancer showed good attitude/practice regarding the same. Those who had poor knowledge exhibited poor attitude/practice. This difference was statistically highly significant $(\mathrm{p}<.001)$. This observation is comparable with some international studies ${ }^{14,15,16}$.

\section{CONCLUSION}

The knowledge regarding cervical cancer among the participants was not satisfactory. Only $20 \%$ respondents named cervical cancer as the leading cancer among women and about $40 \%$ ranked it as $2 \mathrm{n}^{\mathrm{d}}$ leading cancer. Only $20 \%$ women knew that early marriage and multiple marriages might cause cervical cancer but a vast number of respondents did not have any idea regarding the casing factors of cervical carcinoma. Although most of the participants believed that cervical cancer is dangerous disease few really knew that it is preventable. One-third of the respondents could name VIA or Pap's smear as the means of cervical cancer screening. Most of the respondents $(82.7 \%)$ did not undergo cervical cancer screening as they thought the screening test was not necessary. Respondents with higher education level and more educated husband possessed good knowledge regarding cervical cancer. Higher education level was positively correlated with good attitude/practices. Respondents of good socio-economic status showed better attitude/practice than poor status. The respondents who had good knowledge about cervical cancer showed good attitude/practice regarding the same. Those who had poor knowledge exhibited poor attitude/practice.

\section{DISCLOSURE}

All the authors declared no competing interest. 


\section{REFERENCES}

1. The cancer research institute of Bangladesh. The epidemiological study 1976-81. Dhaka. NICRH:1995.

2. Gray H. Reproductive organs of the female. In: Williams PL, Dysor M, editors. Gray's anatomy 37th ed. UK ELBS. 1989;1440-1445.

3. $\quad$ Last RJ. The uterain Anatomy. Regional and Applied. 7th ed. U.K ELBS. 1984; 334-338.

4. Parking DM, Pisani P, Frlay J. Estimates of worldwide incidence of eighteen major cancers in 1985, Int J. Cancer. 1993; 54:594-606.

5. Ferdous J, Khatun S, Hosain F, Pervin S. Nahar. Epidemio-pathological study of cancer cervix in Bangabandhu Sheikh Mujib Medical University. Bangladesh Onc. J. 2009; 4 (1): 26 - 30.

6. Jeffcoate N. Tumors of the cervix uteri. In: Bhatia N, editor. Jaffcoates principles of Gynecology 5th ed. U.K. Arnold. 2001;447-465.

7. Dewhurst J. Pre-malignant and malignant disease of the cervix. In: Edmonds DEK, editor. Dewhurst's Textbook of Obstetrics and Gynaecology for post graduates London. 1999;572.

8. Tran NT, Taylor R, Choe S et al. Knowledge, Attitude and Practice (KAP) Concerning Cervical Cancer and Screening among Rural and Urban Female Healthcare Practitioners in the Democratic People's Republic of Korea. Asian Pacific J Cancer Prev. 2011;12: 3023-3028.

9. Arevian M, Noureddin S, Kabakian T et al. A survey of knowledge, attitude and practice of cervical screening among Lebanese/American women. 1997; 45(1):16-22

10. Bakemeier RF, Krebs LU, Murphy JR et al. Attitude of Colorado Health professionals toward breast and cervical cancer screening in Hispanic women. Journal of national cancer institute Monograph. 1995; 18:95 - 100.

11. World Health Organization. National cancer control programmes: Policies and managerial guidelines, 2nd ed. Geneva. WHO; 2002.

12. De Nooijer J, Lechner L, de Vries H. A qualitative study on detecting cancer symptoms and seeking medical help: an application of Andersen's model of total patient delay. Patient Educ. Counsel. 2001;42: 145-147.

13. Mutyaba T, Mmiro FA, Weiderpass E. Knowledge, attitudes and practices on cervical cancer screening among the medical workers of Mulago Hospital, Uganda. BMC Medical Education. 2006;6:13.

14. Mandal S, Sen A, Kar S, Roy K, Hait A. Distribution of cancer patients according to time taken from starting day of symptoms to reporting at a regional cancer institute in Eastern India. Asian Pac. J. Cancer Prev. 2001; 2: 281-286.

15. Thippeveeranna C, Mohan SS, Singh LR, Singh NN. Screening procedure among nurses in a tertiary hospital in north eastern India. Asian Pacific Journal of Cancer Prevention. 2013; 14: 849-852.

16. Tran NT1, Choe S2, Taylor R et al. Knowledge, Attitude and Practice (KAP) Concerning Cervical Cancer and Screening among Rural and Urban Women in Six Provinces of the Democratic People's Republic of Korea. Asian Pacific J Cancer Prev. 2011;12: 3029-3033. 